\title{
Revisiting the $S$-allele Nomenclature in Sweet Cherry (Prunus avium) Using RFLP Profiles
}

\author{
Nathanael R. Hauck and Amy F. Iezzoni \\ Department of Horticulture, Michigan State University, East Lansing, MI 48824 \\ Hisayo Yamane and Ryutaro Tao ${ }^{1}$ \\ Laboratory of Pomology, Graduate School of Agriculture, Kyoto University, Kyoto 606-8502, Japan
}

\begin{abstract}
AdDitional InDEX wORDS. gametophytic self-incompatibility, $S$-locus genotyping, $S$-RNase, Rosaceae
Abstract. Correct assignment of self-incompatibility alleles ( $S$-alleles) in sweet cherry (Prunus avium $\mathbf{L}$.) is important to assure fruit set in field plantings and breeding crosses. Until recently, only six $S$-alleles had been assigned. With the determination that the stylar product of the $S$-locus is a ribonuclease (RNase) and subsequent cloning of the $S$-RNases, it has been possible to use isoenzyme and DNA analysis to genotype $S$-alleles. As a result, numerous additional $S$-alleles have been identified; however, since different groups used different strategies for genotype analysis and different cultivars, the nomenclature contained inconsistencies and redundancies. In this study restriction fragment-length polymorphism (RFLP) profiles are presented using HindIII, EcoRI, DraI, or XbaI restriction digests of the $S$-alleles present in 22 sweet cherry cultivars which were chosen based upon their unique $S$-allele designations and/or their importance to the United States sweet cherry breeding community. Twelve previously published alleles $\left(S^{1}, S^{2}, S^{3}, S^{4}, S^{5}\right.$, $S^{6}, S^{7}, S^{9}, S^{10}, S^{11}, S^{12}$, and $S^{13}$ ) could be differentiated by their RFLP profiles for each of the four restriction enzymes. Two new putative $S$-alleles, both found in 'NY1625', are reported, bringing the total to 14 differentiable alleles. We propose the adoption of a standard nomenclature in which the sweet cherry cultivars 'Hedelfingen' and 'Burlat' are $S^{3} S^{5}$ and $S^{3} S^{9}$, respectively. Fragment sizes for each $S$-allele/restriction enzyme combination are presented for reference in future $S$ allele discovery projects.
\end{abstract}

Self incompatibility (SI) is a common mechanism in flowering plants which prevents self-fertilization and promotes outcrossing (de Nettancourt, 1977). In gametophytic self-incompatibility (GSI), SI is determined by a single, multi-allelic locus, called the $S$-locus in which the compatibility of a cross is determined by the haploid genome of the pollen and the diploid genome of the pistil. In GSI, pollen tube growth is arrested if the pollen tube has a $S$ allele in common with one of the two $S$-alleles in the style. The $S$ locus is composed of multiple genes, one of which is a RNase $(S$ RNase) which is expressed only in the pistil. A second gene which is hypothesized to be expressed specifically in the pollen, has yet to be determined from any GSI species.

Sweet cherry (Prunus avium) fertilization is controlled by a GSI system and therefore, knowledge of the $S$-allele composition of a tree is crucial for compatible pollination and fruit set. Knight (1969) named six $S$-alleles $\left(S^{1}, S^{2}, S^{3}, S^{4}, S^{5}\right.$, and $\left.S^{6}\right)$ and categorized the cultivars into 13 compatibility groups and a Group $\mathrm{O}$, which included cultivars that were SI but able to pollinate cultivars in all the other groups. As is the case with other reported GSI systems, the stylar $S$-allele component in SI members of the Rosaceae family is an $S$-RNase (Boskovic and Tobutt, 1996; Broothaerts et al., 1995; Burgos et al., 1998; Ishimizu et al., 1996; Sassa et al., 1992, 1996; Tao et al., 1997, 1999; Tomimoto et al., 1996; Ushijima et al., 1998; Yamane et al., 1999). In sweet cherry, RNase isoenzymes (Boskovic et al., 1997) and cDNA sequences (Tao et al.,1999) have been associated with the stylar $S$-allele RNases.

\footnotetext{
Received for publication 30 Oct. 2000. Accepted for publication 25 June 2001. We thank K. Tobutt, R.L. Andersen, C. Choi, B. Lay, and G. Lang for providing plant material, P. Wiersma, K. Tobutt, C. Choi, and R.L. Andersen for sharing their research results prior to publication, and G. Lang, J. Olmstead, H. Sassa, and $\mathrm{K}$. Ushijima for critical reviews of this manuscript. The cost of publishing this paper was defrayed in part by the payment of page charges. Under postal regulations, this paper therefore must be hereby marked advertisement solely to indicate this fact.

${ }^{1}$ Corresponding author; e-mail: rtao@kais.kyoto-u.ac.jp.
}

Sour cherry ( $P$. cerasus L.), which is a hybrid tetraploid species between sweet cherry and ground cherry ( $P$. fruticosa Pall), consists of self-compatible and self-incompatible individuals; however, unlike sweet cherry, control of SI in sour cherry is unknown. Our long term goal is to determine the genetic control of SI in sour cherry (Yamane et al., 2001). We hypothesize that a similar RNase stylar component is present in sour cherry and that sweet and sour cherry may share common $S$-alleles. However, before embarking upon $S$-allele discovery in sour cherry, we needed to have a clear definition of the $S$-alleles that had been identified in sweet cherry.

A review of the sweet cherry $S$-allele literature revealed that potentially similar sweet cherry $S$-alleles had been assigned differing nomenclature (Boskovic and Tobutt, 1996; Boskovic et al., 1997; Choi et al., 2000; Knight, 1969; Schmidt and Timmann, 1997; Schmidt et al., 1999; Tao et al., 1999; Tehrani and Lay, 1991; Wiersma et al., 2001; Yamane et al., 2000). The confusion seems to originate from the initial incorrect classification of 'Hedelfingen' and 'Burlat' into Group VII with the assigned $S$ alleles, $S^{4} S^{5}$ (Knight, 1969). Since 'Hedelfingen' and 'Burlat' are cross compatible, they should have not been assigned to the same group. Tehrani and Lay (1991) recognized the $S$-allele misclassification of 'Hedelfingen' and assigned it to Group O. Boskovic et al. (1997) proposed that 'Hedelfingen' contains the $S^{3}$ - and $S^{5}$-alleles. Crosses done in Germany confirmed that 'Hedelfinger' ('Hedelfingen') was $S^{3} S^{5}$ while 'Burlat' was determined to contain neither $S^{4}$ nor $S^{5}$ (Schmidt and Timmann, 1997). 'Burlat' was assigned the $S$-alleles $\left(S^{3} S^{x}\right)$ where $S^{x}$ represented a novel $S$-allele (Schmidt et al., 1999). In this manuscript we propose the adoption of the $S^{3} S^{5}$ nomenclature for 'Hedelfingen' as proposed by Boskovic et al. (1997), Schmidt and Timmann (1997) and Schmidt et al. (1999). Therefore the objective of this research was to use restriction fragment-length polymorphisms (RFLPs) to characterize 12 sweet cherry $S$-alleles that had been published previously, as well as to characterize two unique $S$ alleles, and to propose the adoption of a standard nomenclature 
(A)

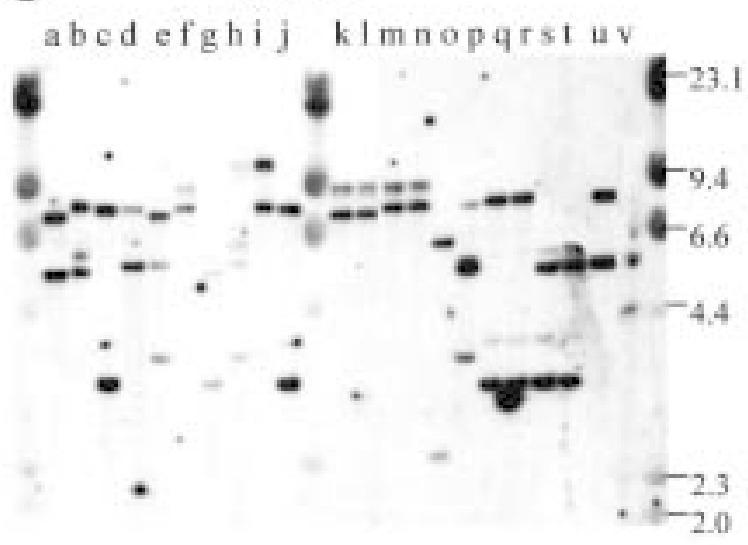

(B)

Dral

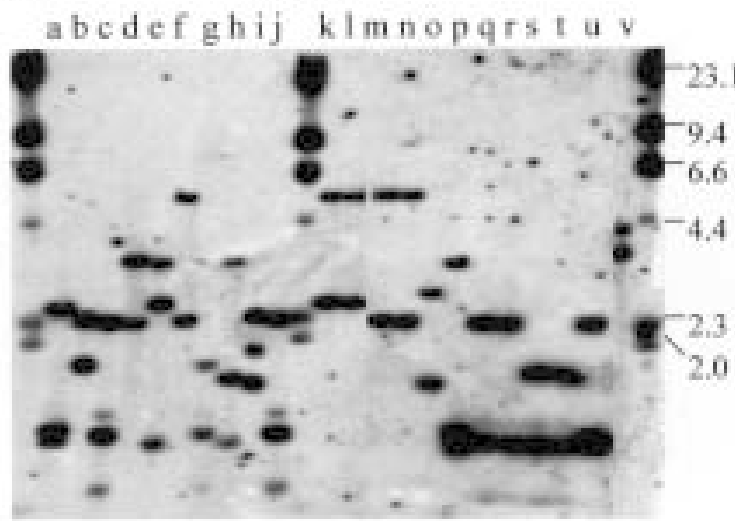

abcdefghij kImnopqrstuv

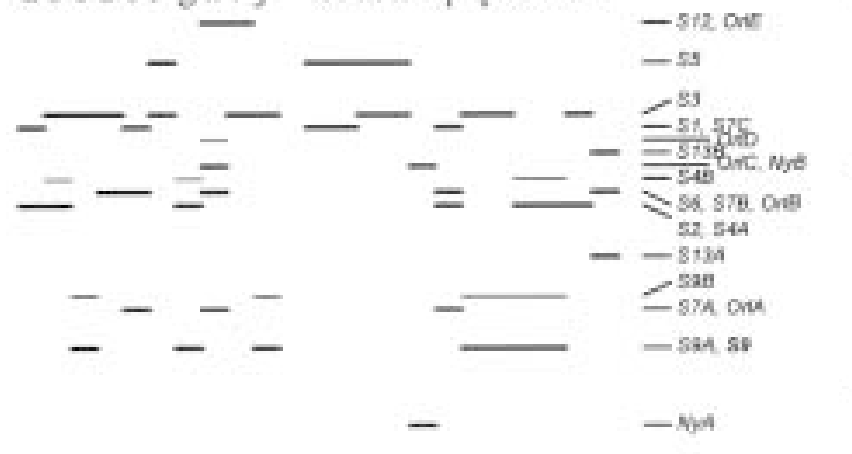

abcdefghij klmoopqrstuv

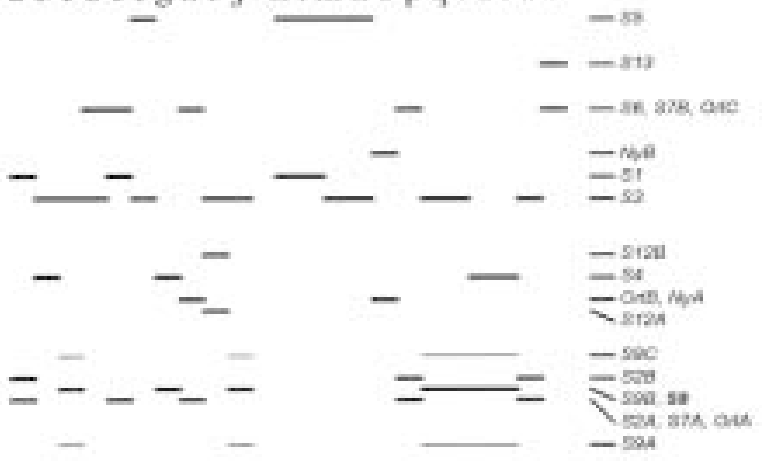

Fig. 1. Genomic DNA blot analysis and schematic representation of the genomic blot of 22 sweet cherry cultivars. Six micrograms of Genomic DNA was digested by (A) HindIII, (B) DraI, (C) EcoRI, or (D) XbaI blotted to membrane and hybridized to the cDNA encoding $S^{6}$-RNase. Lambda/HindIII marker was used for size determination. (a) 'Early Rivers' $\left(S^{l} S^{2}\right)$, (b) 'Napoleon' $\left(S^{3} S^{4}\right)$, (c) 'Burlat' $\left(S^{3} S^{9}\right)$, (d) 'Gold' $\left(S^{3} S^{6}\right)$, (e) 'Charger' $\left(S^{l} S^{7}\right)$ (f) 'Gaucher' $\left(S^{3} S^{5}\right)$, (g) 'Inge' $\left(S^{4} S^{9}\right),(\mathrm{h})$ 'Orleans 171' $\left(S^{10} S^{l 1}\right)$, (i) 'Schneider's $\left(S^{3} S^{12}\right)$, (j) 'Mona' $\left(S^{3} S^{9}\right),(\mathrm{k})$ 'Seneca' $\left(S^{1} S^{5}\right),(\mathrm{l})$ 'Valera' $\left(S^{l} S^{5}\right),(\mathrm{m})$ 'Hedelfingen' $\left(S^{3} S^{5}\right),(\mathrm{n})$ 'Nadino $\left(S^{3} S^{5}\right)(\mathrm{o})$ 'NY1625' $\left(S^{u} S^{v}\right)$, (p) 'Guigne d'Annonay' $\left(S^{2} S^{7}\right)$, (q) 'Chelan' $\left(S^{3} S^{9}\right)$, (r) 'Tieton' $\left(S^{3} S^{9}\right)$ (s) 'PMR-1' $\left(S^{4} S^{9}\right)$, (t) '8007-2' $\left(S^{4} S^{9}\right)$, (u) 'Cavalier' $\left(S^{2} S^{3}\right)$, and (v) 'Noble' $\left(S^{6} S^{13}\right)$. Orl represents $S^{10}$ and $S^{I l}$ found in 'Orleans 171 '. Ny represents $S^{u}$ and $S^{v}$ found in 'NY1625'. If more than one fragment corresponds to an allele, A is used to designate the smallest fragment, B the next smallest, etc. The fragments corresponding to the $S^{9}$ allele from 'Inge' are bold, whereas the fragments corresponding to the $S^{9}$ allele from 'Burlat' are not bold.
(C)

EcoRI

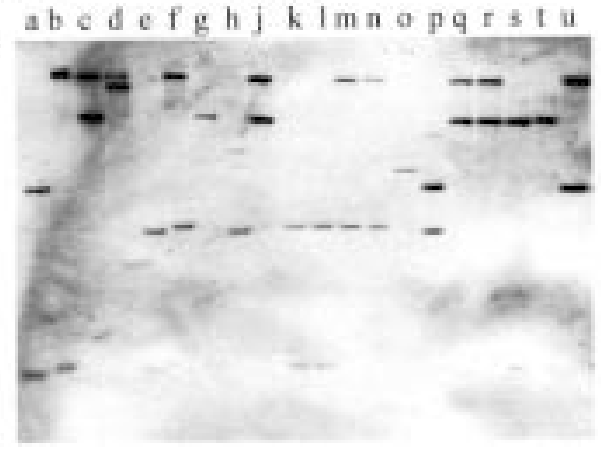

(D)

Xhal

a b c d efg hi j m p
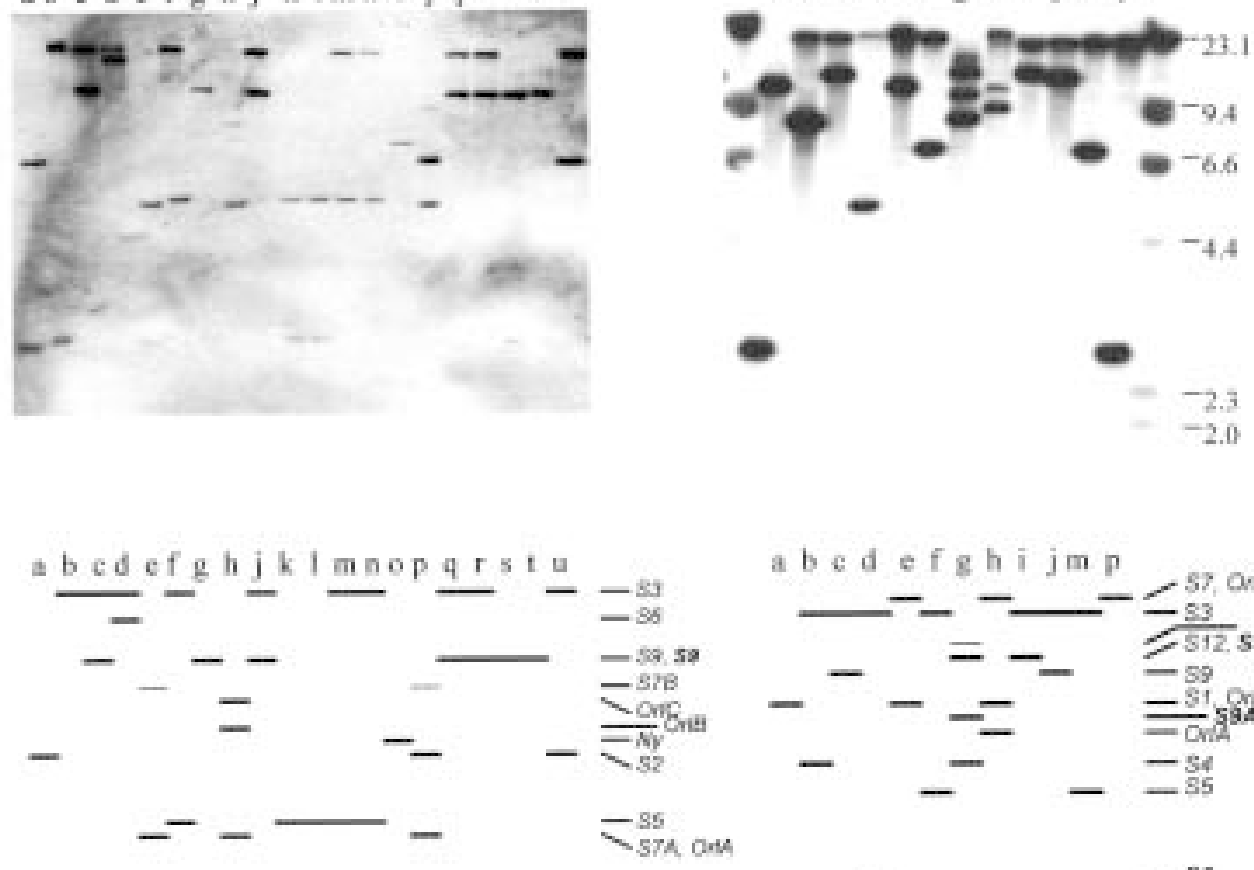

a b c d e f g h i jm p

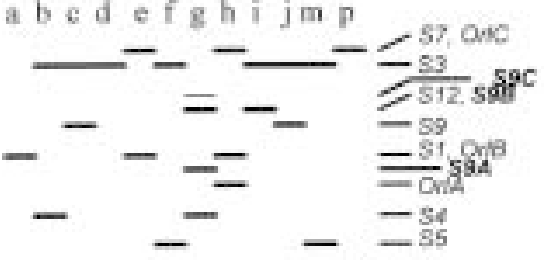

$-56$

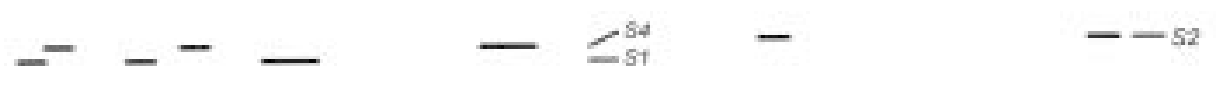


for these $S$-alleles. In addition, the $S$-genotypes of five new cultivars important to the United States sweet cherry breeding community are reported. Fragment sizes for each $S$-allele/restriction enzyme combination are also presented so this information can be used as a reference in future $S$-allele discovery projects.

\section{Materials and Methods}

Plant material. Young leaf tissue was collected from 22 sweet cherry cultivars in the spring. Leaves of 'Napoleon', 'Cavalier' and 'Gold' were collected at the Michigan State University Northwest Horticultural Research Station, Traverse City, Mich. Leaves of 'Charger', 'Gaucher', 'Inge', and 'Orleans 171' were kindly provided by K. Tobutt (East Malling, United Kingdom). Leaves of 'Early Rivers', 'Burlat', 'Schneiders', 'Seneca', 'Valera', 'Hedelfingen', 'Nadino', 'NY1625', and 'Guigne d'Annonay' were kindly provided by C. Choi and R. L Andersen (Geneva, N.Y.). Leaves of 'Noble' were kindly provided by B. Lay (Vineland, Ontario, Canada). Leaves of 'Chelan', 'Tieton', PMR-1, and PC-8007-2 were kindly provided by G. Lang (Prosser, Wash.). Leaves of 'Mona' (DPRU 2046) were obtained from the U.S. Department of Agriculture National Clonal Repository, Davis, Calif. Where possible, the leaf material was placed immediately on dry ice. All frozen and fresh leaf material was lyophilized and stored at $-20{ }^{\circ} \mathrm{C}$ until needed for DNA isolation.

DNA ISOLATION. Total DNA was isolated from young leaves using the CTAB method described by Stockinger et al. (1996).

GeNOMIC DNA BLOT ANALYSIS. Six micrograms of DNA was digested with either HindIII, EcoRI, DraI, or XbaI (Boehringer Mannheim Biochemicals, Indianapolis, Ind.), run on $0.9 \%$ agarose gel for $36 \mathrm{~h}$ at $30 \mathrm{~V}$, and transferred to a nylon membrane (Hybond-N+, Amersham, Piscataway, N.J.) according to Wang et al. (1998). Polymerase chain reaction (PCR) amplified fragments of the $S^{6}$-RNase cDNA from sweet cherry (Tao et al., 1999) were used as the probe. Probes were radiolabelled with ${ }^{32} \mathrm{P}-\mathrm{dCTP}$ (DuPont, Boston) using the random primer hexamer-priming method described by Feinberg and Vogelstein (1983). After hybridization at $60^{\circ} \mathrm{C}$ for $16 \mathrm{~h}$ and high stringency washes $(2 \times$ 30 min with $2 \times \mathrm{SSC}$ and $1 \%$ SDS followed by $2 \times 30$ min with $0.2 \times \mathrm{SSC}$ and $0.5 \% \mathrm{SDS}$ at $60^{\circ} \mathrm{C}$ ), bound radioactivity resulting from hybridizations was detected with X-ray film.

PCr amplification of S-Alleles. PCR was performed on the sweet cherry cultivars using two primer pairs: SI-19 (5' CCA CCG ACC AAC TGC AGA GT 3') / SI-20 (5' TGG TAC GAT TGA AGC GT 3'), and SI-31 (5' STT STT GST TTT GCT TTC TTC 3')/SI-32 (5' CAT AGG CCA TGR ATG GTG 3'), which were designed by Wiersma et al. (2001). The PCR conditions were identical to those used by Wiersma et al. (2001). PCR reactions were run in a DNA Thermal Cycler 480 (Perkin Elmer, Norwalk, Conn.), the resulting PCR mixtures were run on $0.9 \%$ agarose gels, and the DNA bands were visualized by ethidium bromide staining.

\section{Results and Discussion}

Twenty-two sweet cherry cultivars were analyzed by RFLP analyses using HindIII, EcoRI, DraI, or XbaI restriction digestions (Fig. 1). The four RFLP analyses gave consistent results, and it was possible to distinguish 14 different putative $S$-alleles with each of the four restriction enzymes (Table 1).

The $S$-genotypes of 'Early Rivers' $\left(S^{1} S^{2}\right)$, 'Napoleon' $\left(S^{3} S^{4}\right)$ and 'Gold' $\left(S^{3} S^{6}\right)$ have not been questioned in the literature since first published (Knight, 1969) (Table 2). The RFLP fragment sizes for the $S^{1}, S^{2}, S^{3}, S^{4}$, and $S^{6}$ alleles following HindIII and EcoRI digests agree with those of Tao et al. (1999) with only slight variations due to enhanced resolution since in the present study the fragments were separated for a longer period of time on the agarose gel. In the HindIII digest, this enabled $S^{l}$ to be distinguished from $S^{3}$ while $S^{2}, S^{4}$, and $S^{6}$ were distinguished from

Table 1. Sizes of DNA restriction fragments for sweet cherry $S$-alleles used in this study

\begin{tabular}{|c|c|c|c|c|}
\hline \multirow[b]{2}{*}{$S$-allele } & \multicolumn{4}{|c|}{ Size $(k b)$} \\
\hline & HindIII & EcoRI & DraI & $X b a \mathrm{I}$ \\
\hline 1 & 8.7 & 1.5 & 2.5 & 13.0 \\
\hline 2 & 5.6 & 4.4 & $0.8,1.0$ & 2.6 \\
\hline 3 & 8.8 & 13.1 & 2.3 & 20.0 \\
\hline 3 'Gaucher'z & 8.8 & 13.1 & 2.3 & 20.0 \\
\hline 4 & $5.6,6.1^{v}$ & 1.8 & 1.8 & 8.8 \\
\hline 5 & 9.4 & 3.5 & 5.3 & 6.8 \\
\hline 6 & 5.8 & 11.0 & 3.5 & 5.5 \\
\hline 7 & $3.5,5.8,8.7$ & $3.3,6.0^{v}$ & $0.8,3.45$ & 21.0 \\
\hline 9 & 3.1 & 7.9 & 0.9 & $10.0,16.0,18.0$ \\
\hline 9 'Burlat'y & $3.1,4.0^{\mathrm{v}}$ & 7.9 & $0.6^{\mathrm{v}}, 0.9,1.2^{\mathrm{v}}$ & 15.0 \\
\hline 10 or $11^{x}$ & $3.5,5.8,6.4,6.6^{v}, 12.1$ & $3.3,5.0,5.5$ & $0.8,1.6,3.5$ & $9.4,13.0,21.0$ \\
\hline 12 & 12.1 & $--^{\mathrm{u}}$ & $1.5,1.9$ & 16.0 \\
\hline 13 & $4.6,6.5$ & --- & 4.4 & --- \\
\hline $\mathrm{u}$ or $\mathrm{v}^{\mathrm{w}}$ & $2.5,6.4$ & 4.8 & $1.6,2.7$ & --- \\
\hline
\end{tabular}

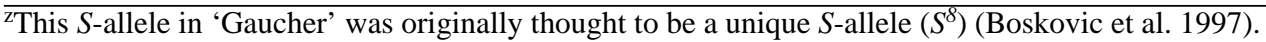

yThis $S$-allele in 'Burlat' was originally thought to be a unique $S$-allele $\left(S^{x}\right)$ (Schmidt et al., 1999).

xThese are the two $S$-alleles in 'Orleans 171'. Restriction fragments for $S^{10}$ and $S^{11}$ were grouped together because it could not be determined which fragments corresponded to each $S$-allele.

wThese are the two putative unique $S$-alleles in 'NY1625'. Restriction fragments for $S^{u}$ and $S^{v}$ were grouped together because it could not be determined which fragments corresponded to each $S$-allele.

vDenotes bands that were very faint.

"Missing data. 
Table 2. $S$-allele genotypes of 17 sweet cherry cultivars used in this study.

\begin{tabular}{llr}
\hline \hline Cultivar & $S$-allele genotype & Other published nomenclature \\
\hline 'Early Rivers' & $1,2^{\mathrm{z}}$ & \\
'Napoleon' & $3,4^{\mathrm{z}}$ & $4,5^{\mathrm{z}}, 3, \mathrm{x}^{\mathrm{w}}, 3,15^{\mathrm{v}}$ \\
'Hedelfingen' & $3,5^{\mathrm{y}, \mathrm{x}}$ & $3, \mathrm{x}^{\mathrm{w}}$ \\
'Nadino' & $3,5^{\mathrm{x}}$ & $1, \mathrm{x}^{\mathrm{w}}$ \\
'Seneca' & 1,5 & $1, \mathrm{x}^{\mathrm{w}}, 1,15^{\mathrm{v}}$ \\
'Valera' & $1,5^{\mathrm{x}, \mathrm{u}}$ & \\
'Gold' & $3,6^{\mathrm{z}}$ & \\
'Charger' & $1,7^{\mathrm{t}}$ & \\
'Guigne d'Annonay' & $2,7^{\mathrm{s}}$ & \\
'Gaucher' & $3,5^{\mathrm{s}}$ & \\
'Inge' & $4,9^{\mathrm{t}}$ & $5, \mathrm{z}^{\mathrm{w}}$ \\
'Orleans 171' & 10 & $11^{\mathrm{t}}$ \\
'Schneiders' & $3,12^{\mathrm{s}}$ & $3,13^{\mathrm{v}}, 3, \mathrm{y}^{\mathrm{w}}$ \\
'Burlat' & $3,9^{\mathrm{s}}$ & $3, \mathrm{x}^{\mathrm{x}}, 4,5^{\mathrm{z}}, 3,5^{\mathrm{w}, \mathrm{v}, \mathrm{r}}$ \\
'Mona' & 3,9 & $2,14^{\mathrm{v}}$ \\
'Noble' & $6,13^{\mathrm{s}}$ & $6, ?^{\mathrm{v}}, 1,6^{\mathrm{w}}$ \\
'NY1625' & $\mathrm{u}, \mathrm{v}^{\mathrm{q}}$ & $4, \mathrm{x}^{\mathrm{w}}$ \\
\hline
\end{tabular}

${ }^{\mathrm{Z}}$ Knight (1969).

'Boskovic and Tobutt (1996).

${ }^{x}$ Schmidt et al. (1999).

${ }^{\text {w}}$ Choi et al. (2000).

${ }^{v}$ Wiersma et al. (2001).

"Way (1968).

'Boskovic et al. (1997).

sooskovic and Tobutt (2001).

rTao et al. (1999).

q'NY1625' contained two alleles that did not appear in any of the other sweet cherry cultivars. They have temporarily been named $S^{u}$ and $S^{\nu}$.

one another, and in the EcoRI digest, this enabled $S^{1}$ to be distinguished from $S^{4}$. Each of these five $S$-alleles exhibits just one fragment with the exception of the $S^{4}$ - and $S^{2}$-alleles, which exhibit two fragments following HindIII and DraI digests, respectively (Table 1, Fig. 1).

As reported by Boskovic et al. (1997), 'Charger' $\left(S^{1} S^{7}\right)$ and 'Inge' $\left(S^{4} S^{9}\right)$ each exhibit one new $S$-allele. These alleles, called $S^{7}$ and $S^{9}$, displayed from one to three unique fragments per allele following Southern hybridization (Table 1, Fig. 1). PCR of the $S^{7}$ allele using the primer pair SI19/SI20 did not amplify any fragment; whereas, a fragment of 425 base pairs (bp) (similar to the $S^{2}, S^{9}$, and $S^{12}$ alleles) was amplified when using the primers SI31/SI32 (Fig. 2). $S^{9}$ produced one 745 bp amplification product and two fragments of $425 \mathrm{bp}$ (similar to $S^{2}, S^{7}$, and $S^{12}$ alleles) and 615 bp, respectively, when amplified with SI19/SI20 and SI31/ SI32.

The presence of two unique $S$-alleles in 'Orleans 171 ' $\left(S^{10} S^{11}\right)$ also agrees with that of Boskovic et al. (1997). RFLP analysis of 'Orleans 171 ' produced either three or five fragments, depending on what restriction enzyme was used (Table 1, Fig. 1) and the fragment patterns did not match that of any known $S$-alleles. It could not be determined which RFLP fragments represent the $S^{10}$ versus the $S^{11}$ alleles since differential cultivars, such as $S^{3} S^{10}$ and $S^{3} S^{11}$ are not available. Neither $S^{10}$ nor $S^{11}$ could be amplified using either of the PCR primer pairs, SI19/SI20 or SI31/SI32 (Fig. 2). These results support the conclusion that 'Orleans 171' contains two unique $S$-alleles.

'Noble' was initially assigned the $S$-alleles $S^{1}$ and $S^{6}$ (Choi et al., 2000), but was later found to contain $S^{6}$ and an unique $S$-allele,

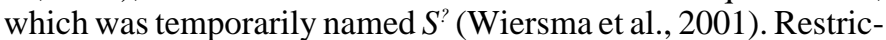
tion digestion of 'Noble' with either HindIII or DraI produced fragments that did not match any found in other cultivars (Table
1, Fig. 1). Boskovic and Tobutt (2001) named this allele $S^{13}$. In order to remain consistent with the European nomenclature, we suggest retaining the genotype of $S^{6} S^{13}$ for 'Noble'.

The $S$-genotypes of the other cultivars in Table 2 have been more difficult to determine and much of this difficulty can be traced to the initial misclassification of 'Hedelfingen' and 'Burlat' (Knight, 1969). All authors agree that 'Hedelfingen' and 'Nadino' have a $S^{3}$ allele and that 'Seneca' and 'Valera' have an $S^{1}$ allele. It is the second common allele present in these four selections that has been assigned conflicting nomenclature. Choi et al. (2000) called this allele $S^{x}$. Wiersma et al. (2001) have named this 'Hedelfingen' allele $S^{15}$. Both groups of researchers called the 'Burlat' allele $S^{5}$. However, both Boskovic et al. (1997) and Schmidt et al. (1999) called the allele in 'Hedelfingen' $S^{5}$ prior to either of these publications. Therefore, we recommend that $S^{5}$ be adopted as the standard nomenclature for the allele present in 'Hedelfingen' and also in 'Nadino', 'Seneca', 'Valera', and 'Gaucher' (Table 2). This $S^{5}$ allele exhibited just one fragment when digested with any of the four restriction enzymes (Table 1, Fig. 1).

The unique $S$-allele present in 'Burlat' that was called $S^{5}$ (Choi et al., 2000; Tao et al., 1999; Wiersma et al., 2001) and $S^{x}$ (Schmidt et al., 1999) should be renamed. Recently, this $S$-allele has been sequenced, and found to have an identical sequence to the $S^{9}$ allele found in 'Inge' (T. Sonneveld, personal communication). Therefore, we propose the $S$-allele nomenclature for 'Burlat' be $S^{3} S^{9}$. The RFLP profiles of the $S^{9}$ allele in 'Burlat' are similar to the profiles of the $S^{9}$ allele from 'Inge' following digestion with HindIII, EcoRI, and DraI with the only differences being the presence of extra faint bands in the 'Burlat' allele when digested with HindIII or DraI (Table 1, Fig. 1). This can be explained by differential length of exposure or differing amounts of DNA in 

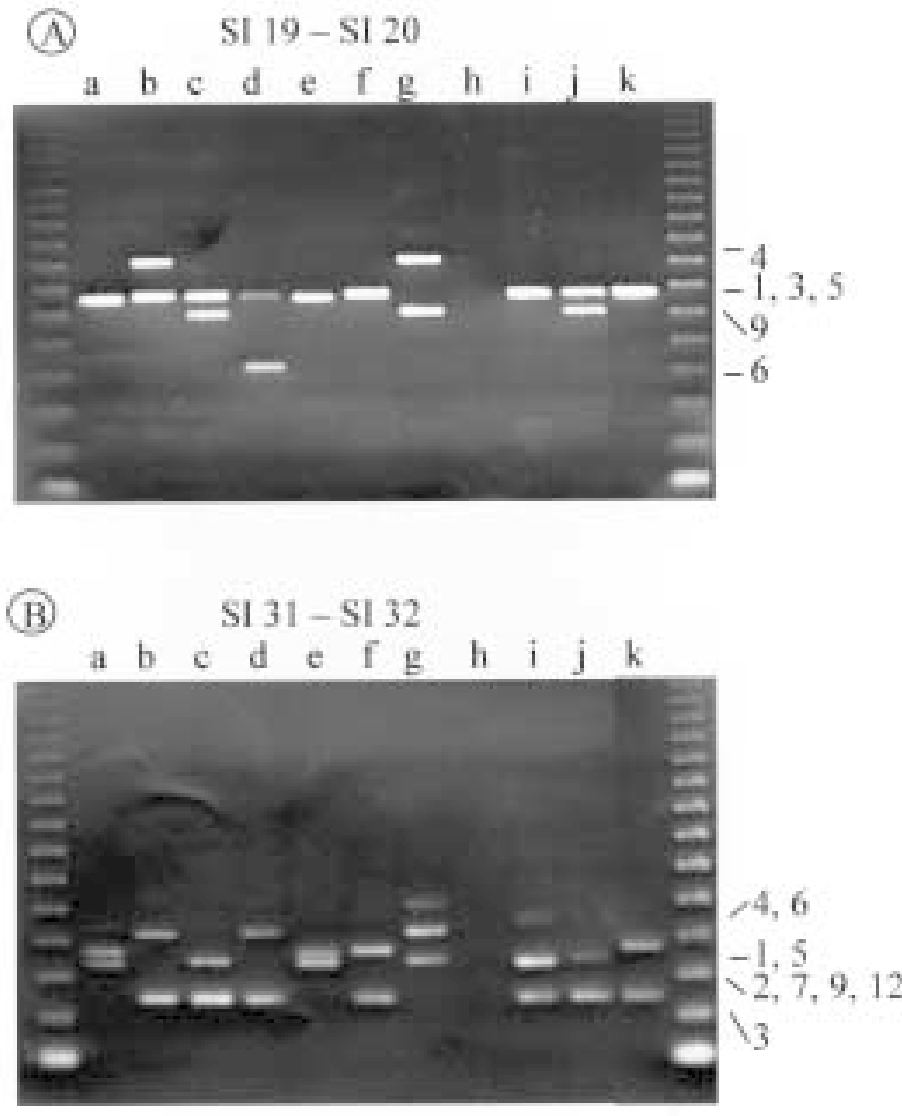

Fig. 2. PCR analysis of $S$-alleles from sweet cherry. Genomic DNA was PCR amplified using two primer sets: (A) SI19/20 and (B) SI31/32. A 123 bp DNA ladder was used for size determination. (a) 'Early Rivers' $\left(S^{l} S^{2}\right)$, (b) 'Napoleon' $\left(S^{3} S^{4}\right)$, (c) 'Burlat' $\left(S^{3} S^{9}\right)$, (d) 'Gold' $\left(S^{3} S^{6}\right)$, (e) 'Charger' $\left(S^{l} S^{7}\right)$ (f) 'Gaucher' $\left(S^{3} S^{5}\right)$, (g) 'Inge' $\left(S^{4} S^{9}\right)$, (h) 'Orleans 171' $\left(S^{10} S^{11}\right)$, (i) 'Schneider's $\left(S^{3} S^{12}\right)$, (j) 'Mona' $\left(S^{3} S^{9}\right)$, and $(\mathrm{k})$ 'Hedelfingen' $\left(S^{3} S^{5}\right)$.

the digestion reaction. However, the profiles of the $S^{9}$ alleles in 'Burlat' and 'Inge' are significantly different after digestion with $X b a \mathrm{I}$. This presents a shortcoming of RFLP analysis for $S$-allele genotyping. If the restriction enzyme cut site(s) resulting in the polymorphism(s) are not within the $S$-RNase, but instead are located in the regions flanking the $S$-RNase, it is possible that identical $S$-alleles could exhibit different RFLP fragments.

'Mona' used in this research has the same genotype as 'Burlat' $\left(S^{3} S^{9}\right)$ (Fig. 1 and 2). This contradicts the finding by Wiersma et al. (2001) that the $S$-genotype of 'Mona' is $S^{2} S^{14}$. The probable explanation is that the 'Mona' trees from which the leaves were collected for each study (the USDA Clonal Repository, Davis, Calif. and Vineland, Ontario, Canada, respectively) were not the same cultivar. These conflicting results reinforce the importance of not only knowing the purported cultivar, but also the source in case identities are mistaken across locations.

Using PCR data, Choi et al. (2000) determined that 'Guigne d'Annonay' contained an allele that differed from any previously reported $S$-allele and thus named it $S^{z}$. The HindIII, EcoRI, DraI, and $X b a \mathrm{I}$ RFLP analyses all suggest that the $S^{z}$ allele in 'Guigne d'Annonay' is the same as the $S^{7}$ allele in 'Charger' (compare lanes e and p on Fig. 1). Therefore, we propose that the actual $S$-genotype of 'Guigne d'Annonay' should be $S^{2} S^{7}$ (Table 2). Similarly, Yamane et al. (2000) used RFLP analyses and $S$-RNase patterns on 2D-PAGE to discover a novel $S$-allele in the cultivar, Hinode (syn. Early Purple). Based on their RFLP patterns after digestion with
EcoRI or HindIII restriction enzymes, this novel $S$-allele also appears to be $S^{7}$.

'Schneiders' has been reported to contain an additional unique $S$-allele, named $S^{y}$ by Choi et al. (2000), $S^{13}$ by Wiersma et al. (2001), and $S^{12}$ by Boskovic and Tobutt (2001). In order to remain consistent with the European nomenclature, we suggest retaining the genotype of $S^{3} S^{12}$ for 'Schneiders'. $S^{12}$ exhibited two fragments following DraI digest and one fragment following HindIII and XbaI digests (Table 1).

Boskovic et al. (1997) presented the RNase isoenzyme patterns for five new $S$-alleles: $S^{7}, S^{8}, S^{9}, S^{10}$, and $S^{11}$. Whereas our RFLP and PCR analyses support the conclusion that $S^{7}, S^{9}, S^{10}$, and $S^{11}$ are unique $S$-alleles, these analyses did not provide evidence that $S^{8}$, which is supposedly present in 'Gaucher', is truly a new $S$-allele. None of the four restriction digests were able to detect a difference between $S^{3}$ and $S^{8}$ (Table 1, Fig. 1). PCR amplification using the primer pairs SI19/SI20 and SI31/ SI32 was also unable to differentiate between $S^{3}$ and $S^{8}$ (Fig. 2). Both the $S^{3}$ and $S^{8}$ alleles produced a fragment of 825 or $300 \mathrm{bp}$ when amplified with SI19/SI20 or SI31/SI32, respectively. Recent cloning and sequencing of the $S^{8}$ allele has shown that the sequence for the $S^{3}$ and $S^{8}$ RNases are identical (Sonneveld et al., 2001). Therefore, the $S$-allele designation for 'Gaucher' should be $S^{3} S^{5}$ rather than $S^{5} S^{8}$.

The RFLP patterns from the HindIII, EcoRI, and DraI RFLP analyses suggest that the selection 'NY1625' contains two $S$ alleles represented by one fragment each that are not found in any other cultivar (lane o in Fig. 1A-C; Table 1). PCR amplification of 'NY1625' using the primer pair SI19/SI20 confirms the presence of at least one unique $S$-allele in 'NY1625' as a single 670 bp fragment (data not presented) was produced, which is different from all known $S$-alleles. However, using PCR, Choi et al. (2000) reported that the $S$-genotype for this selection was $S^{4} S^{x}\left(S^{4} S^{5}\right.$, using the proposed nomenclature) which would be expected given the parentage of 'NY1625' ('Hedelfingen' $S^{3} S^{5}$ X 'Emperor Frances' $S^{3} S^{4}$ ) (Choi, 1999). It is possible that the DNA sample contained some polysaccharide which altered the efficiency of the restriction digests and PCR amplifications. However, it is also likely that the DNA used in these RFLP analyses was mistakenly not collected from 'NY1625'. We propose that these two $S$-alleles be temporarily named $S^{u}$ and $S^{v}$ until crossing data confirms that they are indeed unique $S$-alleles.

Table 3 shows the $S$-genotypes of four new selections from Washington State University and a new cultivar from Michigan. Both 'Chelan' and 'Tieton' are $S^{3} S^{9}$, while PMR-1 and PC-80072 are $S^{4} S^{9}$. Choi et al. (2000) reported that the $S$-genotype of 'Chelan' is identical to that of 'Burlat', which agrees with the RFLP data. The other three cultivars/selections have not been genotyped previously. PMR-1 has been confirmed to be SI (G. Lang, personal communication), thus, this breeding line must contain $S^{4}$ as opposed to the fertile $S$-allele, $S^{4 m}$. The pedigree of PC-8007-2 suggests that it contains the $S^{4 m}$ allele; however,

Table 3. S-genotypes for five Washington State University and Michigan sweet cherry selections.

\begin{tabular}{lc}
\hline \hline Selection & $S$-allele genotype \\
\hline 'Chelan' & 3,9 \\
'Tieton' & 3,9 \\
PMR-1 & 4,9 \\
PC-8007-2 & 4,9 \\
'Cavalier' & 2,3 \\
\hline
\end{tabular}


crossing data suggests that it is SI. These conflicting results make it currently impossible to determine if PC-8007-2 contains $S^{4}$ or $S^{4 m}$. Currently, there are no molecular methods to differentiate between $S^{4}$ and $S^{4 m}$. Therefore, more crossing data are needed to determine if PC-8007-2 is SI or SC. The genotype of 'Cavalier' is $S^{2} S^{3}$. The pedigree for each of these new cultivars confirm the $S$-genotypes determined by RFLP and listed in Table 3.

PCR has been used by several researchers to differentiate between $S$-alleles. Tao et al. (1999) was able to differentiate between six $S$-alleles using two primer sets. Likewise, Wiersma et al. (2001) could distinguish nine $S$-alleles using two primer sets, with the aid of restriction digestions of the PCR-amplified products. However, these studies did not examine all known $S$ alleles. In the current study, additional $S$-alleles were examined. Some of the new $S$-alleles produced amplification fragments that were the same size as those produced by previously studied $S$ alleles. For example, the SI31/SI32 primer pair could not distinguish between $S^{2}, S^{7}, S^{9}$, and $S^{12}$ (Fig. 2). In addition, neither primer set could amplify $S^{10}$ or $S^{11}$. It is possible that restriction digestion of the PCR products would allow for differentiation between $S^{2}, S^{7}, S^{9}$, and $S^{12}$; however, the digestions would be of no use to identify $S^{10}$ and $S^{11}$, since they are both null alleles. As more $S$-alleles are discovered, the number of null alleles and confounding alleles is likely to increase. Nonetheless, PCR is still a useful tool for obtaining quick confirmation of what $S$-alleles are in the progeny of a cross between known parents. In addition, once new $S$-alleles are discovered and cloned, allele-specific primers could be produced which would allow differentiation of all $S$-alleles by PCR for genotyping projects. However, for $S$-allele discovery projects, a more powerful method for differentiating between $S$ alleles is needed. The potential of RFLP for discovery and identification of new $S$-alleles has been demonstrated by the fact that all $S$-alleles can be distinguished based on their unique banding patterns after digestion with any of the four restriction enzymes used in the present study. However, when interpreting RFLP data, it must be taken into consideration that the $S$-allele probe is hybridizing to fragments that include regions flanking the $S$-RNase. If the flanking regions of two identical $S$-RNases differ for their restriction enzyme cut sites, it is possible that different RFLP profiles may be observed in the cultivars even though the $S$-alleles are not unique, leading to the incorrect assumption that a new $S$-allele has been discovered.

Correct identification of $S$-allele genotype is critical for determining pollen compatibilities for field plantings and breeding crosses. Less than 5 years ago, the presence of only six $S$-alleles had been reported in sweet cherry (Boskovic and Tobutt, 1996; Schmidt and Timmann, 1997). Since the stylar component of the $S$-locus in sweet cherry is believed to be an $S$-RNase, new methods are available to discover new $S$-alleles and $S$-allele discovery has proceeded at a rapid pace. It would not be surprising if many more unique $S$-alleles exist in natural populations of sweet cherry, since other plant species having a GSI system have been reported to have a very large number of $S$-alleles. For example, 37 and 39 different $S$-alleles were reported for evening primrose (Oenothera organensis Munz) (Emerson, 1939) and white clover (Trifolium repens L.) (Atwood, 1944), respectively.

The first $6 S$-alleles from sweet cherry were discovered using crossing data. Since then, all of the subsequent $S$-alleles have been identified using molecular techniques. However, proper verification that each $S$-allele is unique requires crossing data. Unfortunately, as the number of unique $S$-alleles in sweet cherry increases, it becomes more cumbersome to perform all of the necessary diallele crosses. As a result, it is important to have available a molecular technique that can differentiate reliably between all unique $S$-alleles. Perhaps the most accurate method to verify the uniqueness of $S$-alleles, besides crossing, is to compare the amino acid sequences of each $S$-allele. However, sequences have not been reported for all known $S$-RNases. The complete amino acid sequences of $S^{l}(\mathrm{AB} 028153), S^{2}$ (AJ298311), $S^{3}$ (AB010306), $S^{4}$ (AB028154), and $S^{6}(\mathrm{AB} 010305)$ can be found on GenBank (http://www.ncbi.nlm.nih.gov/). Until all amino acid sequences are reported, we propose the use of RFLP analysis to investigate the uniqueness of a $S$-allele. For this to be effective, it is necessary that the RFLP patterns for new $S$-alleles be published for comparison. For example, Table 1 presents the fragment sizes for each of the $S$-alleles as determined by RFLP analysis with HindIII, EcoRI, DraI, or XbaI restriction enzymes. When a putative new $S$-allele is discovered, the researcher can compare its fragment sizes with those presented in Table 1 to determine if the $S$-allele is likely a new allele, or if it matches an already existing $S$-allele. The alternative to comparing data with that presented in this table is to include all known $S$-alleles as controls, but as the number of unique $S$-alleles increases, this will get more cumbersome. This strategy of comparing RFLP fragments with fragments produced for known $S$-alleles in sweet cherry was used to propose five new $S$-alleles in sour cherry (Yamane et al., 2001).

\section{Literature Cited}

Atwood, S. 1944. Oppositional alleles in natural populations of Trifolium repens. Genetics 29:428-435.

Boskovic, R., K. Russell, and K.R. Tobutt. 1997. Inheritance of stylar ribonucleases in cherry progenies, and reassignment of incompatibility alleles to two incompatibility groups. Euphytica 95:221-228.

Boskovic, R. and K.R. Tobutt. 1996. Correlation of stylar ribonuclease zymograms with incompatibility alleles in sweet cherry. Euphytica 90:245-250.

Boskovic, R. and K.R. Tobutt. 2001. Genotyping cherry cultivars assigned to incompatibility groups, by analyzing stylar ribonucleases. Theor. Appl. Genet. (In press.)

Broothaerts, W., G.A. Janssens, P. Proost, and W.F. Broekaert. 1995. cDNA cloning and molecular analysis of two self-incompatibility alleles from apple. Plant Mol. Biol. 27:499-511.

Burgos, L., O. Perez-Tornero, J. Ballester, and E. Olmos. 1998. Detection and inheritance of stylar ribonucleases associated with incompatibility alleles in apricot. Sex. Plant Reprod. 11:153-158.

Choi, C. 1999. On the genetics of self-incompatibility in sweet cherry: Identification of S-genotypes; genetical and physiological effects on self-fertility and breakdown of self-incompatibility. PhD diss., Dept. of Hort. Sci., Cornell Univ., Ithaca, N.Y.

Choi, C., K. Livermore, and R.L. Andersen. 2000. Sweet cherry pollination: Recommendation based on compatibility groups and bloom time. J. Amer. Pomol. Soc. 54:148-152.

de Nettancourt, D. 1977. Incompatibility in angiosperms. Springer, New York.

Emerson, S. 1939. A preliminary survey of the Oenothera organensis population. Genetics 24:524-537.

Feinberg, A.D. and G. Vogelstein. 1983. A technique for radiolabelling DNA restriction fragments to high specific activity. Anal. Biochem. 132:6-13.

Ishimizu, T., Y. Sato, T. Saito, Y. Yoshimura, S. Norioka, T. Norioka, and F. Sakiyama. 1996. Identification and partial amino acid sequences of seven $S$-RNases associated with self-incompatibility of Japanese pear, Pyrus pyrifolia Nakai. J. Biochem. 120:326-334.

Knight, R.L. 1969. Abstract bibliography of fruit breeding and genetics to 1965 in Prunus. Eastern Press, London.

Sassa, H., H. Hirano, and H. Ikehashi. 1992. Self-incompatibility-related 
RNases in styles of Japanese pear (Pyrus serotina Rehd.). Plant Cell Physiol. 33:811-814.

Sassa, H., T. Nishio, Y. Kowyama, H. Hirano, T. Koba, and H. Ikehashi. 1996. Self-incompatibility $(S)$ alleles of the Rosaceae encode members of a distinct class of the T2/S ribonuclease superfamily. Mol. Gen. Genet. 250:547-557.

Schmidt, H. and E.M. Timmann. 1997. On the genetics of incompatibility in sweet cherries 1 . Identification of $S$ alleles in self incompatible cultivars. Gartenbauwissenschaft 62:102-105.

Schmidt, H., B. Wolfram, and R. Boskovic. 1999. Befruchtungsverhältnisse bei Süß kirschen. Erwerbsobstbau 41:42-45 (in German).

Sonneveld, T., T.P Robbins, R. Boskovic, and K.R. Tobutt. 2001. Cloning of six cherry self-incompatibility alleles and development of allele-specific PCR detection. Theor. Appl. Genet. 102:1046-1055.

Stockinger, E.J., C.A. Mulinix, C.M. Long, T.S. Brettin, and A.F. Iezzoni. 1996. A linkage map of sweet cherry based on RAPD analysis of a microspore-derived callus culture population. J. Hered. 87:214-218.

Tao, R., H. Yamane, H. Sassa, H. Mori, T.M. Gradziel, A.M. Dandekar, and A. Sugiura. 1997. Identification of stylar RNases associated with gametophytic self-incompatibility in almond (Prunus dulcis). Plant Cell Physiol. 38:304-311.

Tao, R., H. Yamane, A. Sugiura, H. Murayama, H. Sassa, and H. Mori. 1999. Molecular typing of $S$-alleles through identification, characterization and cDNA cloning for $S$-RNases in sweet cherry. J. Amer. Soc. Hort. Sci. 124:224-233.

Tehrani, G. and W. Lay. 1991. Verification through pollen incompatibility studies of pedigrees of sweet cherry cultivars from Vineland. HortScience 26:190-191.
Tomimoto, Y., T. Nakazaki, H. Ikehashi, H. Ueno, and R. Hayashi. 1996. Analysis of self-incompatibility-related ribonucleases ( $S$-RNases) in two species of pears, Pyrus communis and P. ussuriensis. Sci. Hort. 66:159-167.

Ushijima, K., H. Sassa, R. Tao, H. Yamane, A.M. Dandekar, T.M. Gradziel, and H. Hirano. 1998. Cloning and characterization of cDNAs encoding $S$-RNases in almond (Prunus dulcis): Primary structural features and sequence diversity of the $S$-RNases in Rosaceae. Mol. Gen. Genet. 260:261-268.

Wang, D., R. Karle, T.S. Brettin, and A. F. Iezzoni. 1998. Genetic linkage map in sour cherry using RFLP markers. Theor. Appl. Genet. 97:12171224.

Way, R. 1968. Pollen incompatibility groups of sweet cherry clones. Proc. Am. Soc. Hort. Sci. 92:119-123.

Wiersma, P., Z. Wu, L. Zhou, C. Hampson, and F. Kappel. 2001. Identification of new self-incompatibility alleles in sweet cherry (Prunus avium L.) and clarification of incompatibility groups by PCR and sequencing analysis. Theor. Appl. Genet. 102:700-708.

Yamane, H., R. Tao, H. Murayama, M. Ishiguro, Y. Abe, J. Soejima, and A. Sugiura. 2000. Determining $S$-genotypes of two sweet cherry (Prunus avium L.) cultivars, 'Takasago (Rockport Bigarreau)' and 'Hinode (Early Purple)'. J. Jpn. Soc. Hort. Sci. 69:29-34.

Yamane, H., R. Tao, and A. Sugiura. 1999. Identification and cDNA cloning for $S$-RNases in self-incompatible Japanese plum (Prunus salicina Lindl. cv. Sordum). Plant Biotechnol. 16:389-396.

Yamane, H., R. Tao, A. Sugiura, N.R. Hauck, and A.F. Iezzoni. 2001. Identification and characterization of $S$-RNases in tetraploid sour cherry (Prunus cerasus L.). J. Amer. Soc. Hort. Sci. 126(6):661-667. 